\title{
STUDIES USING HPLC-PDA IN GABAPENTIN $N$-DERIVATIZATION REACTIONS WITH 9-FLUORENYLMETHYL CHLOROFORMATE (FMOC-CL)
}

\author{
Emanoel Hottes ${ }^{\mathrm{a}}$, Carla Regina G. R. Santos ${ }^{\mathrm{b}}$, Heloisa J. M. de Souza ${ }^{\mathrm{b}}$, Marco Edilson F. Lima ${ }^{\mathrm{a}, *, \odot}$ e Rosane N. Castro \\ a'Departamento de Química Orgânica, Instituto de Química,Universidade Federal Rural do Rio de Janeiro, 23890-000 Seropédica \\ - RJ, Brasil

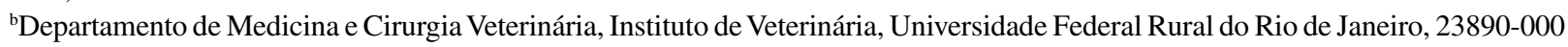 \\ Seropédica - RJ, Brasil
}

Recebido em 01/09/2020; aceito em 14/01/2021; publicado na web em 18/02/2021

\begin{abstract}
FMOC-Cl is a derivatizing agent widely used both in $N$-protection reactions of $\alpha$-amino acids as well as in quantification and detection of amino acids and related molecules using HPLC-PDA or fluorescence analysis. In this work we studied the reaction of FMOC-Cl with gabapentin. However, it was observed that the degradation of gabapentin- $N$-FMOC and FMOC-Cl to FMOC-OH occur simultaneously in presence of the basic reaction medium which is specific for gabapentin derivatization. The degradation reaction is accelerated in temperatures above $45^{\circ} \mathrm{C}$ and also by the time of contact of the reactant and product with basic medium. In this study, gabapentin derivatization reactions were shown to be cleaner and more efficient when an FMOC-Cl/gabapentin ratio of $2: 1$ was used, at $25^{\circ} \mathrm{C}$ over a period of 15 minutes.
\end{abstract}

Keywords: gabapentin; derivatization; degradation; FMOC-Cl; FMOC-OH; HPLC-PDA.

\section{INTRODUCTION}

Derivatization reactions are often carried out in several analytical validation protocols, method development, aiming the detection and quantification of molecules of biological and environmental interest. The purpose of derivatization in chromatographic analyzes is to provide chromophoric groups to molecules that show little or no response to ultraviolet or fluorescence detectors which are the most usual detectors used in high-performance liquid chromatography. The literature reports several reagents used as derivatizing agents in chromatography, for example, 1-fluoro-2,4-dinitrobenzene (FDNB), ${ }^{1} p$-toluenesulfanyl chloride ( $\mathrm{TsCl}),{ }^{2,3}$ 4-chloro-3,5-dinitrobenzotrifluoride $(\mathrm{CNBF}){ }^{4}$ 2,5-dimethoxybenzenesulfonyl chloride (DMOSC), ${ }^{5} p$-nitrobenzoyl chloride (PNBC), ${ }^{6}$ 9-fluorenylmethyl-chloroformate (FMOC-Cl) ${ }^{7-11}$ among others. Within the set of substances applied in derivatization reactions, 9-fluorenylmethyl chloroformate deserves special attention due to it being widely used in the amino acid derivatization reactions. Einarsson reports the efficient application of $\mathrm{FMOC}-\mathrm{Cl}$ in the quatification of proline, sarcosine and hydroxyproline. ${ }^{8}$ Ziegler and Abel also report in their work the application of FMOC-Cl in the quantification of serine, leucine, tryptophan, phenylalanine and glutamic acid. ${ }^{9}$ The detection and quantification of glyphosate, using a method similar to that applied in the present work, in an aqueous medium using FMOC-Cl was also reported by Hottes and co-workers. ${ }^{10}$ In addition to the mentioned compounds, the literature also reports studies applied in the quantification of gabapentin. ${ }^{11}$ Gabapentin (Figure 1) is an anticonvulsant drug used to treat partial seizures, neuropathic pain, in addition to other neurological disorders. However, studies on the application of gabapentin in domestic animals have been developed, aiming to minimize the acute and chronic pain and signs of stress in cat during veterinary examination. ${ }^{12-14} \mathrm{FMOC}-\mathrm{Cl}$, in addition to providing chromophore groups to several molecules allowing their detection via chromatographic methods, it is also applied as protecting group in solid phase peptide synthesis (SPPS). ${ }^{15-19}$

*e-mail: marcoedilson@ gmail.com
FMOC-Cl is stable in acidic medium and undergoes degradation in basic conditions. When in contact with basic reaction conditions, FMOC-Cl is converted into 9-fluorenylmethanol (FMOC-OH, Figure 1) through a hydrolysis followed by decarboxylation reaction, gradually decreasing its capacity as a derivatizing agent, a factor that can compromise the efficiency of the derivatization reaction. Taking into account the aspects related to the FMOC-Cl degradation process in basic medium and how this fact influences the detection and quantification studies of amino acids and related molecules, this work aimed to study the performance of this compound as a derivatizing agent of the drug gabapentin. To evaluate the performance of FMOC-Cl the experiments were conducted having four main variables: time, temperature, concentration of reagents and $\mathrm{pH}$ of the reaction medium. The derivatization reaction was studied in a water/acetonitrile solution, since this is the most common solvent mixture used in the literature for reactions involving amino acids derivatization with $\mathrm{FMOC}-\mathrm{Cl}$, in addition to ensuring the complete solubility of the reagents..$^{20,21}$ The reactions performed were evaluated through HPLC-PDA, since despite being a more complete and robust methodology, when compared to simpler spectrometric methods, such as UV-Vis, it is also widely disseminated and accessible.

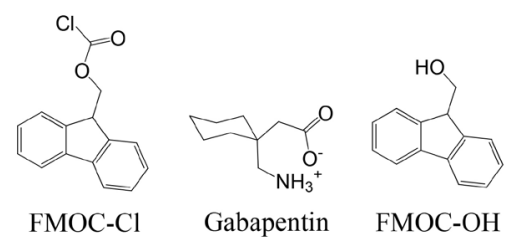

Figure 1. Structures of $\mathrm{FMOC}-\mathrm{Cl}, \mathrm{FMOC}-\mathrm{OH}$ and gabapentin

\section{EXPERIMENTAL}

\section{Materials}

The 9-fluorenylmethyl chloroformate (99\%), $\mathrm{NaOH}, \mathrm{H}_{3} \mathrm{BO}_{3}$, $\mathrm{KCl}, \mathrm{K}_{2} \mathrm{HPO}_{3}, \mathrm{HCl} 36 \%$ and ethyl acetate were obtained from Sigma Aldrich (São Paulo, Brazil) and used without prior purification. 
Acetonitrile (spectroscopic grade) was obtained from Tedia Brazil (Rio de Janeiro, Brazil). All aqueous solutions were prepared with ultrapure water generated by a Milli-Q system (Millipore, Bedford, MA, USA). The ${ }^{1} \mathrm{H}$ and ${ }^{13} \mathrm{C}$ nuclear magnetic resonance spectra were obtained in solution $\left(\mathrm{CDCl}_{3}\right)$ in a $500 \mathrm{MHz}$ Bruker Avance III spectrometer (Rheinstetten, Germany), using TMS as the reference standard for chemical displacements ( $\mathrm{ppm})$. The analyzes by high performance liquid chromatography were performed in a Prominence-Shimadzu equipment (Kyoto, Japan) with an LC20AT pump, SPD-M20A detector, CTO-20A oven, SIL-10AF autosampler, CBM20A controller and LabSolution software. The analyses were performed on a C-18-Allure Organic Acids column $(150 \mathrm{~mm} \times 4.6 \mathrm{~mm} \times 5 \mu \mathrm{m}$, Restek) (Bellefonte, PA, USA), using isocratic elution with $80 \%$ acetonitrile (solvent $\mathrm{B}$ ) and $20 \%$ phosphate buffer at $\mathrm{pH} 2.5$ (solvent A), in a total time of 6 minutes. The flow speed was $1.3 \mathrm{~mL} \cdot \mathrm{min}^{-1}$, oven temperature $40^{\circ} \mathrm{C}$ and injection volume of $20 \mu \mathrm{L}$. Detection was performed at $260 \mathrm{~nm}$.

\section{Optimization of gabapentin derivatization reaction and FMOC-Cl degradation study}

In the reaction process study, several variables that had significant effects on the performance of gabapentin derivatization and on the conversion of FMOC-Cl to FMOC-OH were observed. The parameters evaluated are described in Table 1.

Table 1. Parameters evaluated in the derivatization reaction of gabapentin and in the degradation reaction of FMOC-Cl

\begin{tabular}{cc}
\hline Parameters & Values \\
\hline borate buffer $\mathrm{pH}$ & $8,9.5,10$ \\
FMOC-Cl/Gabapentin ratio & $1: 1,2: 1$ \\
Reaction time $(\mathrm{min})$ & $5,10,15,20,25,30$ \\
Reaction medium temperature $\left({ }^{\circ} \mathrm{C}\right)$ & $25,40,60,80$ \\
\hline
\end{tabular}

Methodology 1 ( single step)

In a $5 \mathrm{~mL}$ volume glass reaction flask equipped with a lid and a magnetic stir bar were added $150 \mu \mathrm{L}$ of gabapentin $\left(1 \mathrm{mg} \mathrm{mL}^{-1}\right)$; $800 \mu \mathrm{L}$ of borate buffer ( $\mathrm{pH} 9.5) ; 113 \mu \mathrm{L}$ of a solution of $2 \mathrm{mg} \mathrm{mL}^{-1}$ FMOC-Cl in acetonitrile ( $\mu$ mols ratio 1:1 FMOC-Cl/gabapentin); or $230 \mu \mathrm{L}$ of a $2 \mathrm{mg} \mathrm{mL}^{-1}$ solution of FMOC-Cl ( $\mu$ mols ratio $2: 1$ FMOC-Cl/gabapentin), and a sufficient amount of acetonitrile (spectroscopic grade) until it reaches $3 \mathrm{~mL}$.

\section{Methodology 2 (two steps)}

In a $5 \mathrm{~mL}$ volume glass reaction flask equipped with a lid and a magnetic stir bar were added $100 \mu \mathrm{L}$ of gabapentin $\left(1 \mathrm{mg} \mathrm{mL}^{-1}\right)$ and $100 \mu \mathrm{L}$ of borate buffer ( $\mathrm{pH}$ 9.5). This solution was allowed to react for 5 minutes at room temperature. Then, $76 \mu \mathrm{L}$ of a $2 \mathrm{mg} \mathrm{mL}^{-1}$ FMOC-Cl solution ( $\mu$ mols ratio 1:1 FMOC-Cl/gabapentin); or $150 \mu \mathrm{L}$ of a $2 \mathrm{mg} \mathrm{mL}^{-1}$ solution of FMOC-Cl ( $\mu$ mols ratio 2:1 FMOC-Cl/ gabapentin), and a sufficient amount of acetonitrile (spectroscopic grade) until it reaches $2 \mathrm{~mL}$.

\section{Preparation of (9H-fluoren-9-yl) methanol (FMOC-OH) from FMOC-Cl}

In a $50 \mathrm{~mL}$ volume round-bottom glass flask were added $50 \mathrm{mg}$ ( $0.194 \mathrm{mmol})$ of FMOC-Cl dissolved in $20 \mathrm{~mL}$ of acetonitrile mixed with $10 \mathrm{~mL}$ of borate buffer $\mathrm{pH} 9.5$. The mixture was allowed to stir for 30 minutes. Then, the product (FMOC-OH) was removed from the reaction medium by partition with ethyl acetate $(3 \times 10 \mathrm{~mL})$, followed by washing with saturated $\mathrm{NaCl}$ solution. The organic phase was dried over anhydrous $\mathrm{Na}_{2} \mathrm{SO}_{4}$, evaporated in a rotary evaporator providing $38 \mathrm{mg}$ of a white solid (m.p.: $\left.104-105^{\circ} \mathrm{C}\right)(85 \%)$. The FMOC-OH product was characterized by ${ }^{1} \mathrm{H}$ and ${ }^{13} \mathrm{C}$ NMR. ${ }^{13} \mathrm{C}-\mathrm{NMR}(125 \mathrm{MHz}$, $\mathrm{CDCl}_{3}$ ) $\delta$ (ppm): 50.00, 65.00, 120.06, 124.67, 127.08, 127.65, 141.56, 144.28. ${ }^{1} \mathrm{H}$ NMR (500 MHz, $\left.\mathrm{CDCl}_{3}\right) \delta(\mathrm{ppm}): 4.08(\mathrm{~d}, 2 \mathrm{H}$, $\left.J 6.12 \mathrm{~Hz}, \mathrm{CH}_{2}\right), 4.15(\mathrm{t}, 1 \mathrm{H}, J 6.0 \mathrm{~Hz}, \mathrm{CH}), 7.36(\mathrm{t}, 2 \mathrm{H}, J 7.56 \mathrm{~Hz}$, Ar -H), 7.43 (t, 2H, J 7.42 Hz, Ar-H), 7.65 (d, 2H, J 7.57 Hz, Ar-H), $7.81(\mathrm{~d}, 2 \mathrm{H}, J 7.56 \mathrm{~Hz}, \mathrm{Ar}-\mathrm{H}), 1.80(\mathrm{OH})$.

\section{Preparation of gabapentin- $N$-FMOC}

In a $50 \mathrm{~mL}$ flask, a solution of gabapentin $(50 \mathrm{mg}, 0.293 \mathrm{mmol})$ in acetonitrile $(10 \mathrm{~mL})$ was treated with $10 \mathrm{~mL}$ of borate buffer $(\mathrm{pH} 9.5)$. This solution was allowed to react for 5 minutes at room temperature, and then FMOC-Cl (155 mg, $0.6 \mathrm{mmol}$ ) was added to the reaction medium. After stirring for 20 minutes at room temperature, the reaction mixture was poured into ice water and gabapentin- $N$-FMOC was obtained by washing the medium with ethyl ether $(3 \times 10 \mathrm{~mL})$ to remove the FMOC-OH, followed by partition with ethyl acetate $(3 \times 10 \mathrm{~mL})$. The ethyl acetate phase was combined, partitioned with $15 \mathrm{~mL}$ of saturated $\mathrm{NaCl}$ solution. The organic phase was dried over anhydrous sodium sulfate and the solvent was evaporated to provide gabapentin-N-FMOC as a white solid weighing $103 \mathrm{mg}$ (90\% yield). The product was characterized by ${ }^{1} \mathrm{H},{ }^{13} \mathrm{C}$ NMR.${ }^{13} \mathrm{C}$ NMR $(125 \mathrm{MHz}$, $\left.\mathrm{CDCl}_{3}\right) \delta(\mathrm{ppm}): 157.76,143.77,141.37,127.74,127.09,125.00$, 120.01, 66.81, 47.36, 33.92, 25.82, 21.31. ${ }^{1} \mathrm{H} \mathrm{NMR}\left(500 \mathrm{MHz}, \mathrm{CDCl}_{3}\right)$ $\delta$ (ppm): 1.0-1.58 (m, 10H, 5CH $) ; 2.19\left(\mathrm{~s}, 2 \mathrm{H}, \mathrm{CH}_{2}\right) ; 2.28(\mathrm{~s}, 2 \mathrm{H}$, $\left.\mathrm{CH}_{2}\right), 4.50\left(\mathrm{~d}, 2 \mathrm{H}, J 6.62 \mathrm{~Hz}, \mathrm{CH}_{2}\right), 4.23$ (t, $\left.1 \mathrm{H}, J 6.60 \mathrm{~Hz}, \mathrm{CH}\right) ; 7.33$ (t, 2H, J 7.25 Hz, Ar-H); 7.43 (t, 2H, J 7.57 Hz, Ar-H); 7.61 (d, 2H, $J 7.25 \mathrm{~Hz}, \mathrm{Ar}-\mathrm{H}) ; 7.78$ (d, 2H, J 7.57 Hz, Ar-H).

\section{RESULTS AND DISCUSSION}

Since the gabapentin structure does not have any chromophore group that allows its detection by ultraviolet spectroscopy, the derivatization reaction with $\mathrm{FMOC}-\mathrm{Cl}$, studied in this work (Figure 2), has the main objective of inserting the FMOC group, allowing thus its detection by the PDA detector.

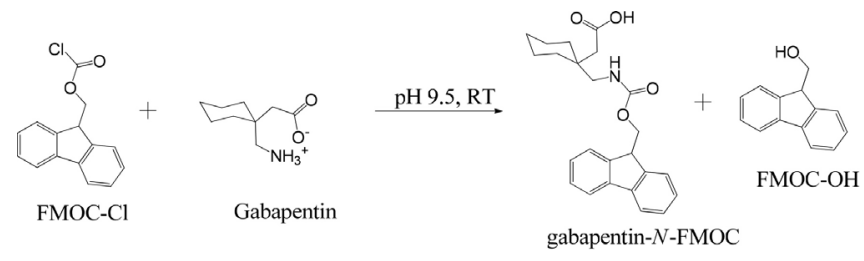

Figure 2. Gabapentin derivatization reaction using $\mathrm{FMOC}-\mathrm{Cl}$

However, the hydrolysis reaction of $\mathrm{FMOC}-\mathrm{Cl}$ to generate FMOC-OH (Figure 2), is a competitive reaction with the formation of gabapentin- $N$-FMOC. Both reactions begin immediately after contact of FMOC-Cl with the basic medium used in the derivatization protocol. Comparatively, the two-stage methodology proved to be more advantageous comparing to the methodology carried out in a single step, as it required shorter contact time between the FMOC-Cl and the basic reaction medium, since it was added only after the initial deprotonation step of gabapentin. Another disadvantage of the methodology in a single step (1:2 v/v, gabapentin-buffer), when compared to the two steps methodology $(1: 1 \mathrm{v} / \mathrm{v}$, gapentin / buffer $)$, was the use of a higher amount of buffer to ensure the appropriate $\mathrm{pH}$ ( $\mathrm{pH} 9.5$ ) for derivatization. The greater amount of buffer $(800 \mu \mathrm{L})$ in the reaction medium used in the single-step methodology impaired 
the derivatization reaction, as it caused the precipitation of $\mathrm{FMOC}-\mathrm{Cl}$, insoluble in aqueous medium, requiring the addition of a greater volume of acetonitrile $(2.0 \mathrm{~mL})$, leading to a higher consumption of this solvent. This increase in the volume of acetonitrile may imply an increase in the analytical costs, especially when you have a significant number of samples to be derivatized.

\section{pH influence}

The gabapentin derivatization reactions were carried out at different pH's (8.0, 9.5 and 10.0), values commonly reported in the literature for derivatizations using FMOC-Cl and also other derivatizing agents. ${ }^{2-6}$ The $\mathrm{pH}$ of the reaction medium is important for the gabapentin $\mathrm{N}$-deprotonation step, so that it can then react with FMOC-Cl, generating the product gabapentin- $N$-FMOC. The best results obtained for deprotonation of gabapentin in the derivatization reaction were observed for $\mathrm{pH}$ values $\leq 9.5$. For lower $\mathrm{pH}$ values, a low rate of formation of the derivatized product was observed, verified by HPLC-PDA. It was also observed that the $\mathrm{pH}$ acts as a modulator for the symmetry of the chromatographic peak. Thus, it was decided to work at $\mathrm{pH} 9.5$ instead of $\mathrm{pH} 10.0$, as it guaranteed efficiency in the derivatization, in addition to less formation of the FMOC-OH and the observation of greater symmetry in the chromatographic peaks. According to results obtained by Hottes and co-workers in the detection and quantification of glyphosate in aqueous solutions treated with clay minerals using $\mathrm{FMOC}-\mathrm{Cl}$ as a derivatizing agent, the reaction showed more efficient responses for the $\mathrm{pH}$ range 9 and 10 . The authors observed a better symmetry pattern of the chromatographic peaks, in addition to a better reproducibility of the applied method. ${ }^{10}$

\section{The FMOC-Cl/gabapentin ratio}

It was observed that the stoichiometric ratio between gabapentin and $\mathrm{FMOC}-\mathrm{Cl}$ in the derivatization reaction directly affects the formation of gabapentin- $N$-FMOC, since gabapentin derivatization reactions and FMOC-Cl degradation reactions are competitive processes. Thus, it was necessary to ensure an adequate concentration of $\mathrm{FMOC}-\mathrm{Cl}$ in the reaction medium, so that the formation of gabapentin- $N$-FMOC was optimized. The strategy used to optimize the derivatization reaction was to monitor the residual FMOC-Cl present at the end of the reaction. It should be noted that the end of the reaction was defined as the time when the variation in the area under the chromatographic peak became constant. For this, the reaction methodology that used the 2:1 ratio $\mathrm{FMOC}-\mathrm{Cl} /$ gabapentin was satisfactory. Previous study using the spectrophotometric method in the ultraviolet region to monitor the derivatization reaction of FMOC-Cl/analytes (glyphosate and aminomethylphosphonic acid), in the ratios $2: 1$ and 5:1, showed that the best results were obtained for the ratio 5:1 (FMOC-Cl : analyte). ${ }^{22}$ However, in the present work, it was possible to observe through the analysis by HPLC-PDA that although the retention times of $\mathrm{FMOC}-\mathrm{Cl}$, FMOC-OH and gabapentin- $N$-FMOC are different, their absorption curves in the ultraviolet (Figure 3 ) are very similar with maximum absorption at $260 \mathrm{~nm}$. This suggests that an analysis by ultraviolet spectrophotometry alone will not guarantee the precise quantification of the analyte, since it will not be able to distinguish the contributions of each of the different species present in the reaction medium. Thus, the use of HPLC-PDA proved to be an efficient and robust analytical tool both in quantifying as in detecting the different components present at the end of the gabapentin derivatization reaction. Similar results were also reported by Hottes and co-workers. The authors reported that in the derivatization of the herbicide glyphosate a 2:1
(FMOC-Cl/glyphosate) ratio was satisfactory in the derivatization reaction even at low temperatures. ${ }^{10}$

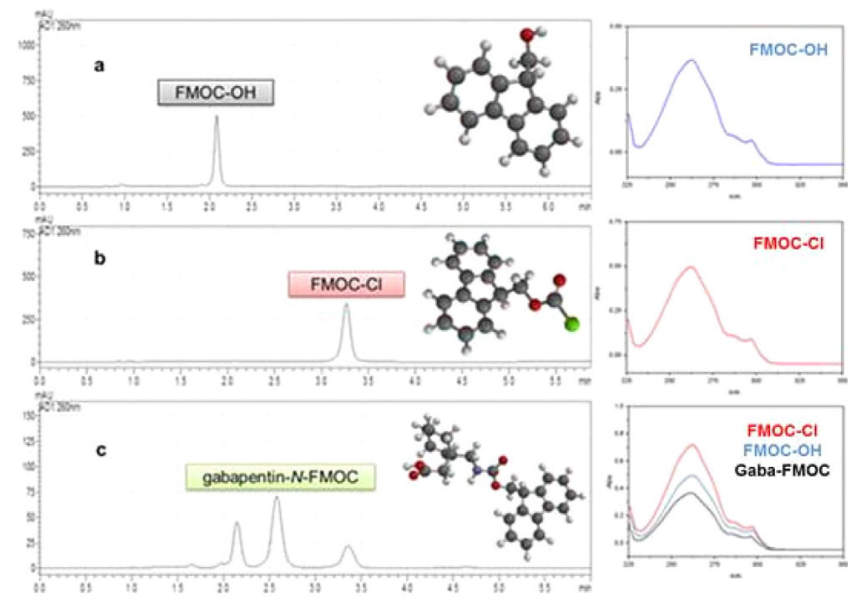

Figure 3. (a) Chromatogram and absorption curve in the FMOC-OH ultraviolet range (b) Chromatogram and absorption curve in the FMOC-Cl ultraviolet range. (c) Chromatogram of the mixture: [FMOC-OH, gabapentin- $N$ - $F M O C$ and $\mathrm{FMOC}-\mathrm{Cl}$; ; and superposition of the absorption curves for $\mathrm{FMOC}-\mathrm{OH}$, gabapentin-N-FMOC and $\mathrm{FMOC}-\mathrm{Cl}$ in the ultraviolet range

\section{Influence of time and temperature}

After establishing the ideal borate buffer $\mathrm{pH}$ (9.5) and FMOC-Cl/ gabapentin ratio $2: 1$, the influence of time and temperature on the gabapentin derivatization process and the degradation of FMOC-Cl were evaluated. Figure 4 shows the areas (\%) related to the formation of the gabapentin- $N$-FMOC adduct as a function of reaction times at different temperatures. Through the analysis of the graphs it was possible to observe a maximum formation of the product gabapentin$\mathrm{N}$-FMOC at $25^{\circ} \mathrm{C}$ and 15 minutes of reaction time. In all cases, a drop in product formation was observed after 15 minutes followed by a concomitant increase in the formation of FMOC-OH. This behavior can be seen in Figure 5. After approximately 15 minutes of reaction, it is no longer possible to observe the presence of $\mathrm{FMOC}-\mathrm{Cl}$ in reactions conducted at $60^{\circ} \mathrm{C}$ and $80^{\circ} \mathrm{C}$, indicating that its concentration is zero. The increase in the concentration of FMOC-OH after 15 minutes can be justified by the degradation of gabapentin- $N$-FMOC in the reaction medium at higher temperatures, since its concentration decreased after 15 minutes of reaction time.

Through analysis of the graphs shown in Figures 4 and 5 the degradation process is influenced not only by the alkaline reaction
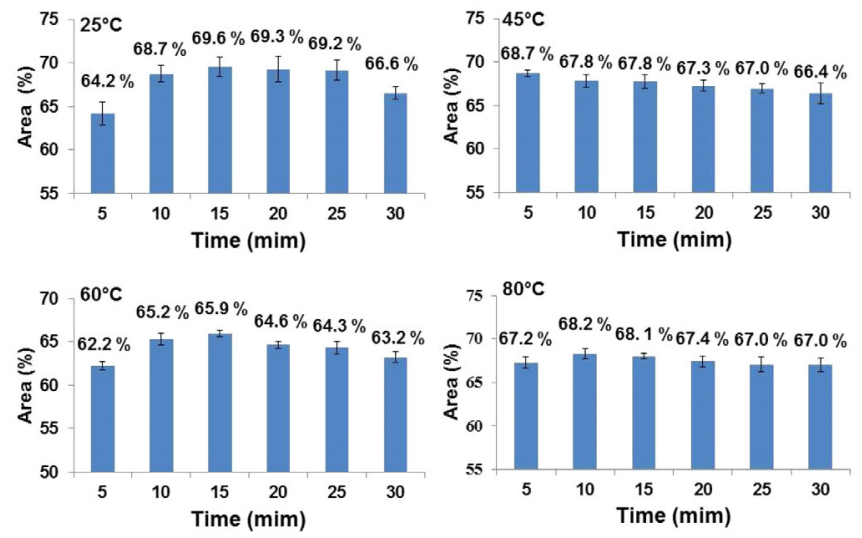

Figure 4. Percentage of product formation (gabapentin-N-FMOC) as a function of time at different temperatures $\left(25^{\circ} \mathrm{C}-80^{\circ} \mathrm{C}\right)$ 
medium, but also by the temperature and reaction time. The higher the temperature, the higher the rate of degradation. By monitoring the area related to the consumption of FMOC-Cl and the appearance of FMOC-OH, it was observed that for temperatures equal to or greater than $60{ }^{\circ} \mathrm{C}$ the degradation process was increased. The same was observed in the appearance of the by-product FMOC-OH: for higher temperature and reaction times, a higher product formation rate was observed. Since it is desired to guarantee the slow degradation of FMOC-Cl in order to increase its performance as a derivatizing agent, it is appropriate to work at room temperature, as can be seen in Figure 4.
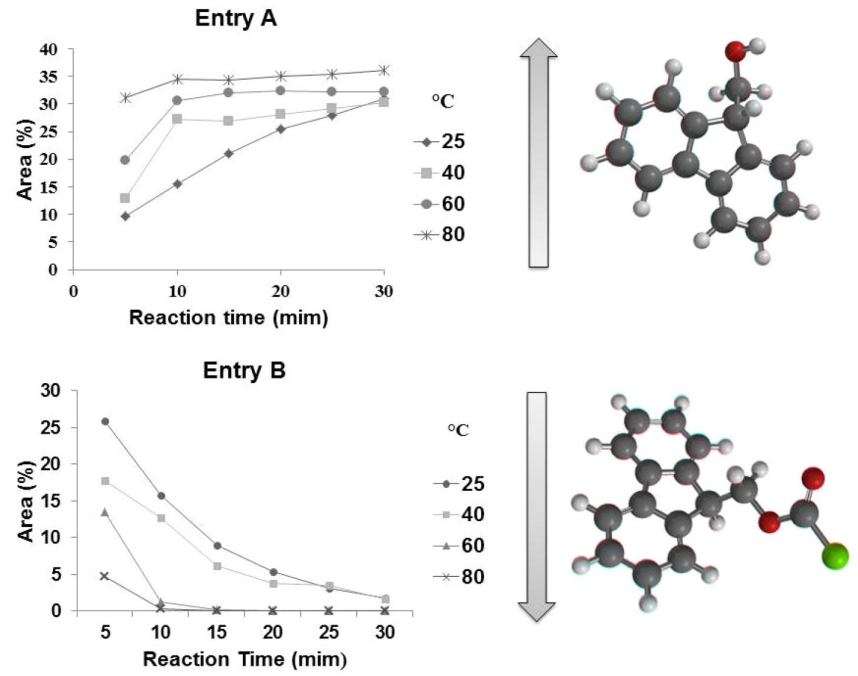

Figure 5. Increase in the formation of FMOC-OH (degradation product, entry A) and a decrease in the concentration of $\mathrm{FMOC}$-Cl (entry B), as a function of time and temperature

\section{CONCLUSIONS}

The derivatization methodology performed in two stages contributes to less formation of the degradation product FMOC-OH, thus favoring the gabapentin derivatization reaction. The derivatization reaction reached its greatest efficiency after 15 minutes for most temperatures, suggesting that reactions conducted at room temperature are satisfactory in amino acid reactions with FMOC-Cl. It is important to note that reactions conducted at room temperature were more practical and more economically viable. The 2:1 FMOC/ gabapentin ratio proved to be quite satisfactory for the derivatization process studied. Finally, the use of the HPLC-PDA technique was a fundamental tool to evaluate all these parameters.

\section{SUPPLEMENTARY MATERIAL}

The ${ }^{1} \mathrm{H}-\mathrm{RMN}$ and ${ }^{13} \mathrm{C}-\mathrm{RMN}$ spectra for FMOC-OH and gabapentin- $N$-FMOC are available at http://quimicanova.sbq.org.br, in PDF format, with free access.

\section{ACKNOWLEDGMENTS}

This study was financed in part by the Coordenação de Aperfeiçoamento de Pessoal de Nível Superior - Brazil (CAPES), $\mathrm{CNPq}$ and FAPERJ. The gabapentin was kindly supplied by Drogavet Pharmacy.

\section{REFERENCES}

1. Lundgren, L. N.; J. Agric. Food Chem. 1986, 34, 535.

2. Corbera, M.; Hidalgo, M.; Salvadó, V.; Wieczorek, P. P.; Anal. Chim. Acta 2005, 540, 3.

3. Khrolenko, M. V.; Wieczorek, P. P.; J. Chromatogr. A 2005, 1093, 111.

4. Qian, K.; He, S.; Tang, T.; Shi, T.; Li, J.; Cao, Y.; Food Chem. 2011, 127, 722.

5. Fanga, F.; Wei, R.; Liua, X.; Intern. J. Environ. Anal. Chem. 2014, 94, 661.

6. Hori, Y.; Fujisawa, M.; Shimada, K.; Sato, M.; Kikuchi, M.; Honda, M.; Hirose, Y.; J. Chromatogr B 2002, 767, 255.

7. Zhu, Y.; Zhang, F.; Tong, C.; Liu, W.; J. Chromatogr. A 1999, 850, 297.

8. Einarsson, S.; J. Chromatogr. A 1985, 348, 213.

9. Ziegler, J.; Abel, S.; Amino Acids 2014, 46, 2799.

10. Hottes, E.; Santos, A. M.; Cardoso, C. M.; Castro, R. N.; Herbst, M. H. In Glyphosate: Chemistry, Uses and Safety Concerns; Quinn, R., ed.; Nova: New York, 2018, cap. 2.

11. Bahrami, G.; Kiani, A.; J. Chromatogr. B 2006, 835, 123.

12. Crociolli, G. C.; Cassu, R. N.; Barbero, R. C.; Rocha, T. L. A.; Gomes, D. R.; Nicácio, G. M.; J. Vet. Med. Sci. 2015, 77, 1011.

13. Van Haaften, K. A.; Forsythe, L. R. E.; Stelow, E. A.; Bain, M. J.; J. Am. Vet. Med. Assoc. 2017, 251, 1175.

14. Guedes, A. G. P.; Meadows, J. M.; Pypendop, B. H.; Johnson, E. G.; Zaffarano, B.; J. Am. Vet. Med. Assoc. 2018, 253, 579.

15. Bot, B. L.; Colliaux, K.; Pelle, D.; Briens, C.; Seux, R.; Clément, M.; Chromatographia 2002, 56, 161 .

16. Melucci, D.; Xie, M.; Reschiglian, P.; Torsi, G.; Chromatographia 1999, 49, 317.

17. Bank, R. A.; Jansen, E. J.; Beekman, B.; te Koppele, J. M.; Anal. Biochem. 1996, 240, 167.

18. Nasholm, T.; Sandberg, G.; Ericsson, A.; J. Chromatogr. A 1987, 396, 225.

19. Ziegler, J.; Abel, S. Amino Acids 2014, 46, 2799.

20. Bahrami, G.; Kiani, A.; J. Chromatogr. B 2006, 835, 123.

21. Almasri, I. M.; Ramadan, M.; Algharably, E.; J. Appl. Pharm. 2019, 9 , 21.

22. Catrinck, T. C. P. G.; Dias, A.; Aguiar, M. C. S.; Silvério. F. O.; Fidêncio, P. H.; Pinho, G. P.; J. Braz. Chem. Soc. 2014, 7, 1194. 